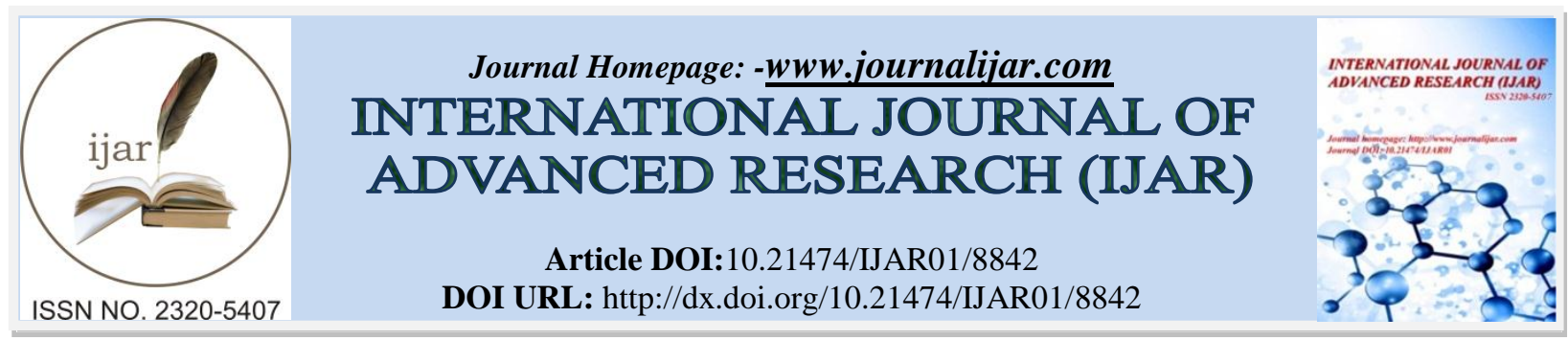

RESEARCH ARTICLE

\title{
TO SCREEN FOR REFRACTIVE ERRORS AND AMBLYOPIA IN CHILDRENWITH INTELLECTUAL DISABILITY UNDER 5 YRS OF AGE WITH PHOTOSCREENER AND COMPARE WITH CYCLOPLEGIC REFRACTION.
}

Col Anirudh Singh and Gp Capt MA Khan.

\section{Manuscript Info}

Manuscript History

Received: 07 February 2019

Final Accepted: 09 March 2019

Published: April 2019

Key words:-

Amblyopia, photoscreener.

\section{Abstract}

A comparison of refraction under cycloplegia with manual streak retinoscopy with autorefractor and photoscreener in children with intellectual disability under 5 years of age was undertaken at a tertiary care hospital. A total of 200 children with intellectual disability were recruited and examined. The study concluded that the photoscreener has various advantages including time saving, easy manipulation, portability and good compliance of targeted children especially those with intellectual disability as compared to retinoscopy examination.

Copy Right, IJAR, 2019,. All rights reserved.

\section{Introduction:-}

Amblyopia screening in children is a daunting task with a large number of cases being missed due to difficulties encountered while examining an uncooperative child; the difficulty level of task increases manifold in children with intellectual disability. Amblyopia screening is usually a part of pre-school vision screening programs which aims to detect amblyopia and related conditions such as strabismus, anisometropia, and refractive errors.

Manual retinoscopy is routinely used for amblyopia screening but it yields variable results due to inter-observer variability ( Safir et al 1970, Zadnik et al 1992) ${ }^{1,2}$. Manual retinoscopy has been a time tested gold standard and has proven efficient in high ametropias especially astigmatism. The drawback being that it is dependant on observer expertise, amount of cycloplegia achieved and patient cooperation. In children the results are much more variable and is virtually a nightmare in children with intellectual disability.

Autorefractors though more accurate with astigmatism, yet are limited by their utility in children and more so when the child has intellectual disability.

A newer modality known as photoscreener has been used in the west over the last decade and has been found to be effective in uncooperative children due to a faster measurements from a distance. Another advantage of photoscreener is measurement without cycloplegia and can also be done by a paramedical or non medical staff, hence screening periods are shorter. Photoscreeners have been used in various screening programmes in the US and has been recognized by both the US Preventive Services Task Force (USPSTF) and the American Academy of Pediatrics (AAP) as a valid screening modality in the children. ${ }^{3}$ 
Comparative study between photoscreeners and autorefraction as well as manual retinoscopy can strengthen the screening protocols and aid in early amblyopia detection and management.

Although few studies have been done on comparison of refraction with autorefractor and photoscreener yet no study has been done in children with intellectual disability where requirement and difficulty level is much more. A comparison of refraction under cycloplegia with manual streak retinoscopy with autorefractor and photoscreener/plusoptix in children with intellectual disability under 5 years of age with due validation will prove to be a useful tool in future amblyopia screening with better detection leading to effective management.

\section{Methods:-}

A total of 200 children with intellectual disability were recruited and examined as part of a larger population-based prospective observational study conducted in the Eye department of our hospital from Jan 2014 to Jan 2017. Children with intellectual disability( mental retardation) attending the paediatric clinic of the hospital who were referred to the paediatric ophthalmology section were included in the study. The inclusion criteria was age between 2 and 5 years and child cooperative for refraction. Exclusion criteria was cases with significant media opacities and retinal abnormalities.

Informed consent was obtained from the parents and approval was obtained from the Ethical committee of hospital. The conduct of the study followed the tenets of the Declaration of Helsinki. All the parents were informed about the details of the study prior to obtaining their consent.

The children were screened in the following sequence: photorefraction was done with the Plusoptix A09 photoscreener with and without cycloplegia. Autorefraction was done with Shin Nippon autorefractor, anterior segment assessment using portable slit lamp, fundus examination and cycloplegic retinoscopy was carried out. Orthoptic examination including Hirschberg test and Krimsky test was done for all cases. Same observer did the manual retinoscopy of all cases to reduce the probability of errors.

The Plusoptix A09 photoscreener was operated by the ophthalmologist himself. The patient was made to sit on the examining chair about one meter in from of the photoscreener in a semi dark room. The camera has a smiling face with a warbling sound to draw the attention of the child. The camera is pointed towards the child and image captured the moment child looks towards the camera and the fixation is recorded by complete green circles. The following measurements are recorded -automatic refraction, pupil size, fixation and interpupillary distance. The Plusoptix A09 photoscreener has a spherical and cylindrical range of $-7.0 \mathrm{D}$ to $+5.0 \mathrm{D}$.If the ocular misalignment is more than $10^{\circ}$ then the measurements cannot be done in the binocular mode but requires a monocular mode setting.

Routine orthoptic examination was done and deviation measured with Hirschberg only as PBCT was difficult to do in children under 5 years of age with intellectual disability. Autorefraction was done using a Shin Nippon Autorefractometer which was followed by anterior segment examination. Thereafter cycloplegic refractionwas done with $1.0 \%$ cyclopentolate drops instilled three times every three minutes and manual refraction done after 45 to 50 minutes.Single examiner did manual refraction and was masked to the one doing autorefraction with photoscreener to exclude bias,

\section{Data analysis:-}

The sample size was calculated using hypothesis testing about difference between means with level of significance as $5 \%$ and power of study as $80 \%$.

The data from Shin Nippon autorefractor and manual streak retinoscopy was analysed using the paired t-tests. A pvalue of $<0.05$ was taken as statistically significant. The spherical equivalent was taken as sphere with half of cylinder.

All statistical analyses were performed using SPSS (version 16.0, IBM-SPSS, USA).

\section{Results:-}

A total of 219 children with intellectual disability were included in the study. Four children were excluded from the study as they were non co-operative for manual refraction and four were excluded due to small pupil size. Plusoptix 
A09 could not measure refraction in six patients as they had either high myopia or hypermetropia ( more than 5 diopter). Five patients were excluded from the study as they had retinal pathology. After excluding these cases, we had 200 cases ie 122 boys and 78 girls.

A total of 122 boys and 78 girls $(n=200$ children) with a mean age of $48.4 \pm 11.1$ months, were taken for the current study. The mean SE as measured by photoscreener was $2.54 \pm 0.83 \mathrm{D}$. The mean SE obtained from the autorefractor was $2.49 \pm 0.71$ whereas with streak retinoscopy it was $2.35 \pm 0.78 \mathrm{D}$. The mean SE obtained from the photoscreener (Plusoptix A09) (2.54 D) was significantly more hyperopic than that of manual retinoscopy (2.36 D) $(\mathrm{p}=<0.001)$ and autorefractor $(2.49 \mathrm{D})(\mathrm{p}=0.001)($ Table $1 \& 2)$. Scatter plot shows the hyperopic overestimation with photoscreener as compared to streak retinoscopy ( Chart 1). Pearson correlation coefficient was $(\mathrm{r}=1 / \mathrm{p}=0.000)$ for manual retinoscopy and $(\mathrm{r}=0.9 / \mathrm{p}=0.000)$ for photoscreener ( both highly statistically significant). There was a mean difference of $+0.18 \mathrm{D}$ between the spherical equivalent results of Plusoptix A09 and that of streak retinoscopy.

Astigmatism was seen in 52 out of 200 cases $(26 \%)$. Astigmatism measured by streak retinoscopy was $-0.55 \pm 0.56$ $\mathrm{D}$ and using the Plusoptix A09 was $-0.50 \pm 0.42 \mathrm{D}$. The difference in cylinder values between streak retinoscopy and photoscreener was not statistically significant.

Table 1:-Paired T-test between the manual retinoscopy and photoscreener

\begin{tabular}{|l|l|r|r|r|r|r|r|}
\hline \multicolumn{2}{|l|}{ Paired T-Test } & \multicolumn{1}{c|}{\begin{tabular}{c} 
Mean \\
\multicolumn{2}{|c|}{}
\end{tabular}} & Mean SE & N & $\begin{array}{c}\text { Std. } \\
\text { Deviation }\end{array}$ & $\begin{array}{c}\text { Mealue } \\
\text { Difference }\end{array}$ & p-value \\
\hline \multirow{2}{*}{ Pair } & MANUAL RETINOSCOPY & 2.36 & 200 & 0.79 & -0.19 & 12.055 & $<0.001$ \\
\cline { 2 - 8 } & PHOTOSCREENER & 2.54 & 200 & 0.83 & & & \\
\hline
\end{tabular}

\begin{tabular}{|c|c|c|c|}
\hline \multicolumn{4}{|c|}{ Descriptive Statistics } \\
\hline & Mean & Std. Deviation & $\mathrm{N}$ \\
\hline MANUAL RETINOSCOPY & 2.3575 & 0.78759 & 200 \\
\hline PHOTOSCREENER & 2.5438 & 0.83367 & 200 \\
\hline \multicolumn{4}{|c|}{ Correlations } \\
\hline & & $\begin{array}{c}\text { MANUAL } \\
\text { RETINOSCOPY }\end{array}$ & PHOTOSCREENER \\
\hline \multirow[t]{3}{*}{ MANUAL RETINOSCOPY } & $\begin{array}{l}\text { Pearson } \\
\text { Correlation }\end{array}$ & 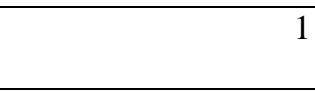 & $.965^{* *}$ \\
\hline & Sig. (2-tailed) & & $<0.001$ \\
\hline & $\mathrm{N}$ & 200 & 200 \\
\hline \multirow[t]{3}{*}{ PHOTOSCREENER } & $\begin{array}{l}\text { Pearson } \\
\text { Correlation }\end{array}$ & $.965^{* *}$ & 1 \\
\hline & Sig. (2-tailed) & 0 & \\
\hline & $\mathrm{N}$ & 200 & 200 \\
\hline
\end{tabular}

Table 2:-Paired T-Test between Manual retinoscopy, autorefractor and photoscreener

\begin{tabular}{|c|c|c|c|c|c|c|c|}
\hline & & Mean & $\mathbf{N}$ & $\begin{array}{c}\text { Std. } \\
\text { Deviation }\end{array}$ & $\begin{array}{c}\text { Mean } \\
\text { Difference }\end{array}$ & t-value & p-value \\
\hline \multirow[t]{2}{*}{ Pair 1} & $\begin{array}{l}\text { MANUAL } \\
\text { RETINOSCOPY }\end{array}$ & 2.36 & 200 & 0.79 & -0.13 & 7.789 & $<0.001$ \\
\hline & AUTOREFRACTOR & 2.49 & 200 & 0.72 & & & \\
\hline \multirow[t]{2}{*}{ Pair 2} & AUTOREFRACTOR & 2.49 & 200 & 0.72 & -0.05 & 3.342 & 0.001 \\
\hline & PHOTOSCREENER & 2.54 & 200 & 0.83 & & & \\
\hline \multirow[t]{2}{*}{ Pair 3} & $\begin{array}{l}\text { MANUAL } \\
\text { RETINOSCOPY }\end{array}$ & 2.36 & 200 & 0.79 & -0.19 & 12.055 & $<0.001$ \\
\hline & PHOTOSCREENER & 2.54 & 200 & 0.83 & & & \\
\hline \multicolumn{8}{|c|}{ Correlations between Manual retinoscopy, autorefractor and photoscreener } \\
\hline \multicolumn{5}{|c|}{ Descriptive Statistics } & & & \\
\hline
\end{tabular}




\begin{tabular}{|l|l|r|r|}
\hline & Mean & Std. Deviation & N \\
\hline MANUAL & 2.3575 & 0.78759 & 200 \\
RETINOSCOPY & & & 200 \\
\hline AUTOREFRACTOR & 2.4912 & 0.71698 & 200 \\
\hline PHOTOSCREENER & 2.5438 & 0.83367 & \\
\hline
\end{tabular}

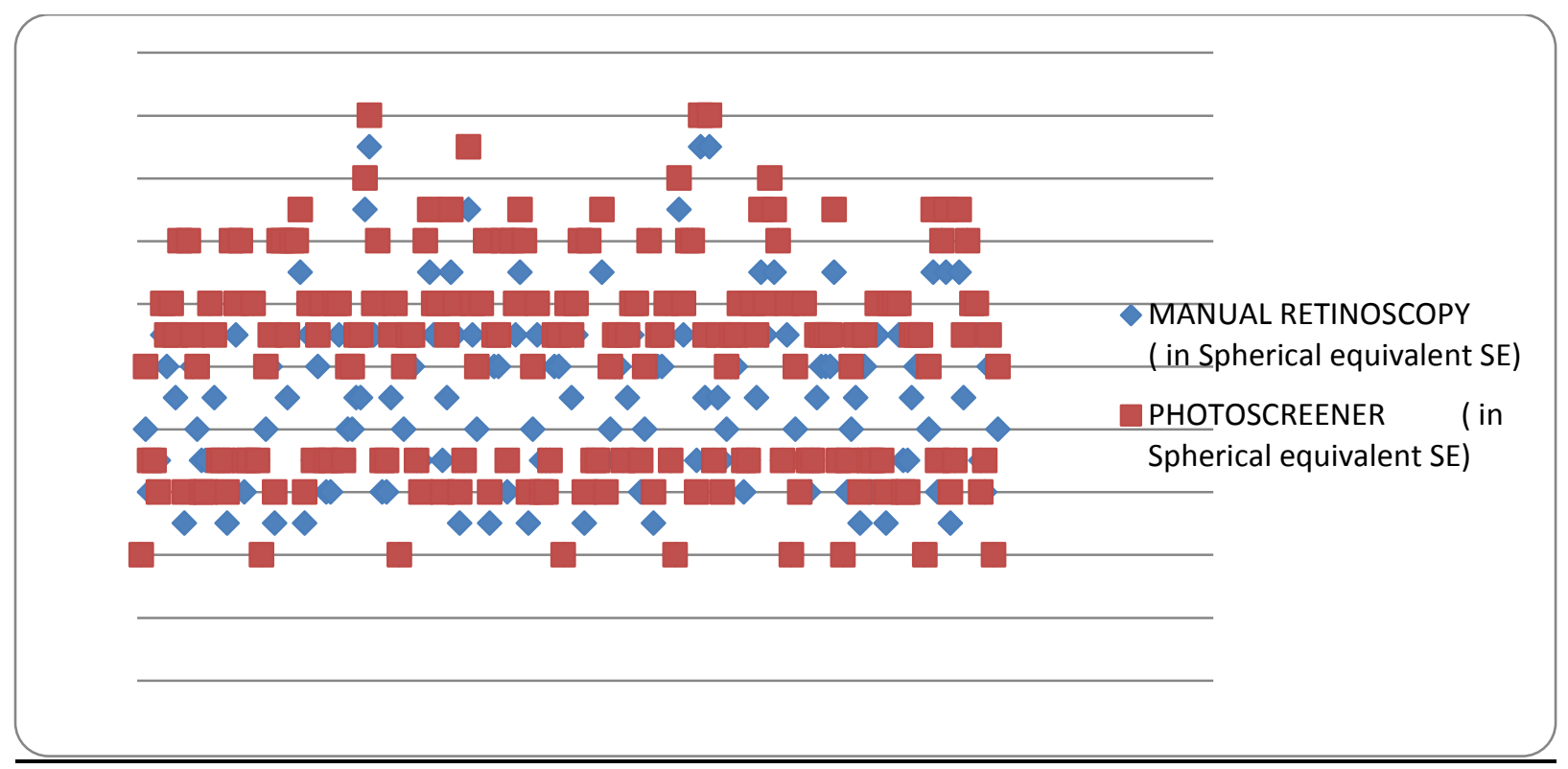

Figure 1:-Scatter plot between manual retinoscopy and photoscreener

\section{Discussion:-}

Photorefraction has been used in few studies only for the early detection of amblyopia, however these studies have shown that photorefraction has high sensitivity and specificity for detection of amblyopia risk factors in children vision screening programmes. ${ }^{4-7}$ Photorefraction has additional advantages of being relatively faster, less dependent on patient cooperation and can be handled by paramedics. The Photoscreener also has advantages while examining children and especially those with intellectual disability. The risk of undetected refractive errors and amblyopia is close to $1 \%$ in children with intellectual disability. ${ }^{8}$ Photoscreener requires just few seconds of steady eye fixation and head immobilization to record all the information. The major limitation is while examining children with high refractive errors( more than 5 diopters), media opacity and occasionally strabismus. In such cases cycloplegic refraction is recommended.

Weseman and Cordoneer et al reported that photorefraction without cycloplegia gives inaccurate readings and also has limitation with high refractive errors. Our study however showed that photoscreeners measured refraction both with and without cycloplegia.

In our study refraction using the photoscreener Plusoptix A09 with and without using a cycloplegic agent was compared with the manual cycloplegic retinoscopy and autorefraction in children with intellectual disability under 5 yrs of age. There was a statistically insignificant difference between the results of Plusoptix A09 and that of streak retinoscopy. Our study showed that there was overestimation of hyperopia with photoscreener as compared to the streak retinoscopy. Abrahamsson et al $^{11}$ and Erdurmus et al ${ }^{12}$ reported that the photorefractor PowerRef II found $0.42 \mathrm{D}$ more hyperopia as compared to retinoscopy or autorefractometry, which is comparable to the $0.18 \mathrm{D}$ found in the present study. However in a study done by Yan X-R et al ${ }^{13}$ photoscreener underestimated hyperopia and overestimated myopia. ${ }^{14,15}$

The photoscreener is easy to use and handle, portable, convenient, time saving and also gives additional information like interpupilary distance, pupil size and strabismus. Also one of the major advantages of photoscreener is in mass screening. Cases of non refractive esotropia can be easily missed by manual retinoscopy and autorefractor as these 
two methods do not measure strabismus separately however these can be easily picked up by photoscreener. Due to these advantages photoscreener is definitely a better modality to screen amblyopia in children with intellectual disability less than 5 yrs of age where children cooperation is also minimal. Photoscreener can be connected to laptop or PC via Bluetooth for a faster data acquisition and data analysis. Cycloplegic retinoscopy on the other hand is time consuming, uses cycloplegic eye drops, and requires a trained optometrist/ophthalmologist, hence is not an optimal approach for amblyopia risk factor screening.

Gabriel et $\mathrm{al}^{19}$ and Choi et $\mathrm{al}^{20}$ reported that no significant stimulation of accommodation occurs during photorefraction and that reliable measurements can be obtained. Our study results showed a strong association between measurements of photoscreener and those with manual cycloplegic refraction except for the slight overestimation of hyperopia. The reason for this overestimation could be due to the slight accommodation which is induced while fixating target from one meter distance.

Dahlmann-Noor et alreported that the photoscreener as a single screening test can miss significant number of children with amblyogenic risk factors. ${ }^{21,22}$ However in our study we also did orthoptic examination and found that it is $100 \%$ sensitive although specificity is less for which photoscreener can be used along with orthoptic examination.

\section{Limitations:}

The feasibility of a diagnostic test is very important in children. In our study photorefraction using plusoptix A09 was not possible in 02 children as they were not cooperative and in 04 due to small pupil size. Plusoptix A09 could not measure refraction in 05 patients as they had either high myopia or hypermetropia i.e., more than manufacturer's range. Also the photoscreener cannot record measurements when the pupil is less than $3 \mathrm{~mm}$ or when it is more than $8 \mathrm{~mm}$ due to lens aberrations.

\section{Conclusion:-}

The photoscreener has various advantages including time saving, easy manipulation, portability and good compliance of targeted children especially those with intellectual disability as compared to retinoscopy examination. $^{23-24}$ Plusoptix A09 photoscreener with the cover or a stereo test can improve overall effectiveness in detecting strabismus. The major limitation of photoscreener (Plusoptix A09) is slight overestimation of hyperopia and underestimation myopia. However no significant difference is seen in astigmatism between Plusoptix A09 and cycloplegic retinoscopy.

\section{References:-}

1. Safir, A., Hyams, L., Philpot, J. and Jagerman, L. S. (1970) Studies in refraction. The precision of retinoscopy. Arch Ophthalmology 84, 49-61.

2. Zadnik, K., Mutti, D. O. and Adams, A. J. (1992) The repeatability of measurements of the ocular component. Invest. Ophthalmol. Vis. Sci. 33, 2325-2333.

3. Salcido AA, Bradley J, Donahue SP. Predictive value of photoscreening and traditional screening of preschool children. J AAPOS. 2005;9:114-120

4. Singman E, Matta N, Tian J, Brubaker A, Silbert D. A comparison of the PlusoptiX S04 and A09 photoscreeners. Strabismus. 2013; 21: 85-87.

5. Ayse YK, Onder U, Suheyla K. Accuracy of Plusoptix S04 in children and teens. Can J Ophthalmol. 2011; 46: $153-157$.

6. Paff T, Oudesluys-Murphy AM, Wolterbeek R, Swart-van den Berg M, de Nie JM, Tijssen E, et al. Screening for refractive errors in children: the plusoptiX S08 and the Retinomax K-plus2 performed by a lay screener compared to cycloplegic retinoscopy. J AAPOS. 2010; 14: 478-483.

7. Saber Moghadam A, Alizadeh R, Zarei-Ghanavati M. Plusoptix S08 sensitivity in detecting strabismus as amblyogenic risk factor. Strabismus. 2103; 21: 230-234.

8. Mirzajani A, Heirani M, Jafarzadehpur E, Haghani H. A comparison of the Plusoptix S08 photorefractor to retinoscopy and cycloretinoscopy. Clin Exp Optom. 2013; 96: 394-399.

9. Wesemann W, Dick B. Accuracy and accommodation capability of a handheld autorefractor. J Cataract Refract Surg. 2000; 26: 62-70.

10. Cordonnier M, Dramaix M. Screening for refractive errors in children: accuracy of the hand held refractor Retinomax to screen for astigmatism. Br J Ophthalmol. 1999; 83: 157-161. 
11. Abrahamsson M, Ohlsson J, Björndahl M, Abrahamsson H. Clinical evaluation of an eccentric infrared photorefractor:The PowerRefractor. Acta Ophthalmol Scand 2003; 81: 605-610.

12. Erdurmus M, Yagci R, Karadag R, Durmus M. A comparison of photorefraction and retinoscopy in children. J AAPOS 2007; 11: 606-611.

13. Yan X-R, Jiao W-Z, Li Z-W, Xu W-W, Li F-J, Wang L-H. Performance of the Plusoptix A09 Photoscreener in Detecting Amblyopia Risk Factors in Chinese Children Attending an Eye Clinic. Lu Z-L, ed. PLoS ONE. $2015 ; 10(6)$

14. Arthur BW, Riyaz R, Rodriguez S, Wong J. Field testing of the plusoptiX S04 photoscreener. J AAPOS 2009;13:51-7.

15. Ayse YK, Onder U, Suheyla K. Accuracy of Plusoptix S04 in children and teens. Can J Ophthalmol. 2011; 46: $153-157$.

16. Rosenfield M, Chiu NN. Repeatability of subjective and objective refraction. Optom Vis Sci 1995; 72: 577579.

17. Paff T, Oudesluys-Murphy AM, Wolterbeek R, Swart-van den Berg M, de Nie JM, Tijssen E, Schalij-Delfos NE. Screening for refractive errors in children: The Plusoptix S08 and the Retinomax K-plus2 performed by a lay screener compared to cycloplegic retinoscopy. J AAPOS 2010; 14: 478-483.

18. Schimitzek T, Wesemann W. Clinical evaluation of refraction using handheld wavefront autorefractor in young and adult patients. J Cataract Refract Surg 2002; 28: 1655-1666.

19. Gabriel GM, Mutti DO. Evaluation of infant accommodation using retinoscopy and photoretinoscopy. Optom Vis Sci 2009; 86: 208-215.

20. Choi M, Weiss S, Schaeffel F, et al. Laboratory, clinical and kindergarten test of a new eccentric infrared photorefractor (PowerRefractor). Optom Vis Sci 2000; 77: 537-548.

21. Dahlmann-Noor AH, et al. Vision screening in children by Plusoptix Vision Screener compared with goldstandard orthoptic assessment. Br J Ophthalmol 2009; 93: 342-345.

22. Dahlmann-Noor AH, Comyn O, Kostakis V, Misra A, Gupta N, Heath J, Brown J et al. Plusoptix Vision Screener: the accuracy and repeatability of refractive measurements using a new autorefractor. Br J Ophthalmol 2009; 93: 346-349.

23. Peterseim MM, Papa CE, Wilson ME, Cheeseman EW, Wolf BJ, Davidson JD, Trivedi RH. Photoscreeners in the pediatric eye office: compared testability and refractions on high-risk children. Am J Ophthalmol. 2014;158:932-8.

24. Bogdănici CM, Săndulache CM, Vasiliu R, Obadă O. Difference of refraction values between standard autorefractometry and Plusoptix.Rom J Ophthalmol. 2016;60:249-254. 